\title{
Clinical Severity Predicts Time to Hospital Admission in Patients with Spontaneous Intracerebral Hemorrhage
}

\author{
Hagen B. Huttner ${ }^{a, b}$ Martin Köhrmann ${ }^{a}$ Elena Tognoni ${ }^{b}$ Eric Jüttler ${ }^{b}$ \\ Gregor Richter ${ }^{c}$ Arnd Dörfler $^{c}$ Udo Reulbach ${ }^{a}$ Teresa Bassemir ${ }^{a}$ \\ Dimitre Staykov $^{a} \quad$ Jürgen Bardutzky ${ }^{a} \quad$ Peter D. Schellinger ${ }^{a} \quad$ Stefan Schwab ${ }^{a}$ \\ ${ }^{a}$ Department of Neurology, University of Erlangen, Erlangen, ${ }^{b}$ Department of Neurology, \\ University of Heidelberg, Heidelberg, and ' Division of Neuroradiology, Department of Radiology, \\ University of Erlangen, Erlangen, Germany
}

\section{Key Words}

Intracerebral hemorrhage $\cdot$ Time window admission • FAST trial

\begin{abstract}
Background: In this study we analyzed whether demographic, clinical and neuroradiological parameters are associated with time to hospital admission in patients with spontaneous intracerebral hemorrhage $(\mathrm{ICH})$. We a priori hypothesized that the earlier a patient was admitted to hospital, the worse the clinical status would be. Methods: Demographic, clinical and neuroradiological parameters of consecutive patients with spontaneous ICH directly admitted to 2 neurological university departments were subjected to correlation, trichotomization and logistic regression analyses for prediction of (i) early hospital admission, and (ii) favorable clinical presentation at admission [dichotomized Glasgow Coma Scale (GCS) score $\geq 9$ ]. Results: We analyzed 157 patients with a median age of 66 (39-93) years. Patient trichotomization according to the GCS revealed a significant difference $(p<0.001)$ between all groups with regard to the time from symptom onset to hospital admission: patients with a GCS score of 3-5 were admitted after 105 (40-300) $\min$ (mean: $113 \pm 53$ ), those with a GCS score of 6-9 after 180
\end{abstract}

(45-420) $\min$ (mean: $184 \pm 95)$ and those with a GCS score of 10-15 after $300(60-1,560)$ min (mean: $324 \pm 367)$. There were significant correlations between (i) hematoma volume and GCS ( $r=-0.632 ; p<0.001$ ); (ii) time to admission and GCS $(r=0.596 ; p<0.001)$, and (iii) Graeb scores for intraventricular hemorrhage and hematoma volume $(r=0.348 ; p<0.001)$. In the multivariate regression model for prediction of time until hospital admission, presence of intraventricular hemorrhage and the GCS score on admission were significant. In the multivariate regression model for prediction of a GCS score of $\geq 9$ on admission, hematoma volume and time until hospital admission were significant parameters. Conclusions: Clinically more severely affected patients were admitted to hospital earlier. This highlights the importance of most rapid diagnosis of $\mathrm{ICH}$. Efforts should be made to get less severely affected patients admitted earlier as they might be ideal candidates for emerging innovative treatments.

Copyright $\odot 2008$ S. Karger AG, Basel

\section{Introduction}

Spontaneous intracerebral hemorrhage (ICH) is associated with high mortality, and hematoma volume is the best predictive factor for outcome [1-3]. In about $35 \%$ of

\section{KARGER}

Fax +4161306 1234 E-Mail karger@karger.ch www.karger.com (c) 2008 S. Karger AG, Basel

1015-9770/08/0256-0533\$24.50/0

Accessible online at:

www.karger.com/ced
Dr. H.B. Huttner

Department of Neurology, University of Erlangen

Schwabachanlage 6

DE-91054 Erlangen (Germany)

Tel. +499131853 4563, Fax +4991318536597, E-Mail hagen.huttner@uk-erlangen.de 
the cases, there is early hematoma growth [4], which probably reflects ongoing bleeding and occurs up to $24 \mathrm{~h}$ after symptom onset [5]. Hematoma growth might be influenced by blood pressure [6] and location of the intracerebral bleeding [7]. Outcome is associated with rapid diagnosis including conservative treatment strategies [8], and surgical evacuation might be beneficial in selected patients with respect to clinical severity and site of the hematoma [9].

Based on these findings, a hemostatic therapy using activated recombinant factor VII was tested and revealed a reduction of hematoma growth and evidence of efficacy when given within $4 \mathrm{~h}$ after onset [10]. While the biological signal could be confirmed, the pivotal phase III trial did not have any impact on outcome [11]. There have only been few studies - with focus on ischemic stroke rather than on ICH - investigating possible associations between time window from symptom onset until hospital admission and severity of clinical presentation [12-14]. In this study we analyzed whether demographic, clinical and neuroradiological parameters are associated with time to admission in patients with ICH. We a priori hypothesized that the earlier a patient was admitted to hospital, the worse the clinical status would be.

\section{Methods}

\section{Patient Selection and Study Design}

This open and observational study was a retrospective analysis of a prospectively organized database and included all consecutive patients with a spontaneous ICH directly admitted to 2 neurological university departments between December 2004 and January $2006(\mathrm{n}=157)$. We did not enroll patients with $\mathrm{ICH}$ associated with tumor, trauma, thrombolysis and oral anticoagulant therapy, or patients with subdural and epidural hematoma, or subarachnoid hemorrhage.

\section{Parameter Acquisition}

Clinical Parameters

We reviewed all medical records of the patients including protocols of the emergency physicians. We precisely documented the time window of hospital admission since the onset of symptoms (in case of wake-up stroke the time of awakening was scored as symptom onset) and noted the first-scored Glasgow Coma Scale (GCS) as assessed by the emergency physician prior to hospital admission, or at our neurological emergency department if admission was not attended by an emergency physician. We a priori decided to group the patients according to their GCS score, (i) by trichotomization (GCS score 3-5; 6-9; 10-15) [9], and (ii) dichotomization into patients with an indication for intubation and mechanical ventilation (GCS score $<9$ ) and those without (GCS score $\geq 9$ ) [15]. Further clinical parameters were gender and age.
Neuroradiological Parameters

ICH was diagnosed immediately after hospital admission by CT or MRI $[16,17]$. Two stroke physicians who were blinded to all clinical data, in particular admission times, reviewed the CT and MRI scans independently and in randomized order and noted the hematoma volume (cubic centimeters), calculated according to the formula for ellipsoids $(\mathrm{ABC} / 2)$, which has been demonstrated to estimate the hematoma volume reliably $[18,19]$. The site of the hematoma was noted; deep (defined to include basal ganglia and thalamic bleedings), lobar and posterior fossa hemorrhages [20]. In case of ventricular involvement (IVH), the Graeb score was measured [21], however, the intraventricular blood portion was not considered for hematoma volume measurement.

\section{Statistical Analysis}

The normal distribution of the data was assessed with the Kolmogorov-Smirnov test. As the data were not normally distributed, nonparametric tests were calculated. Therefore, multigroup comparison was performed using the Kruskal-Wallis test, and correlation analyses with the Spearman-Rank procedure. Moreover, we performed 2 logistic regression models for prediction of (i) time to hospital admission, and (ii) favorable clinical presentation (i.e. GCS score 9-15). The dependent variable was dichotomized using the method of median split. Relevant demographic, clinical and neuroradiological parameters were entered into the aforementioned stepwise forward logistic regression models. The significance level was set at $\alpha=0.05$. The statistical tests were 2-sided. All statistical analyses were performed using the statistical software package SPSS 13.0 (SPSS Inc., Chicago, Ill., USA).

\section{Results}

Demographic and neuroradiologic parameters of all patients are listed in table 1. Patient trichotomization according to the GCS revealed a significant difference between all groups: patients with a GCS score of 3-5 were admitted after 105 (40-300) min (mean: $113 \pm 53$ ), those with a GCS score of 6-9 after $180(45-420)$ min (mean: $184 \pm 95)$ and those with a GCS score of 10-15 after 300 $(60-1,560) \min ($ mean: $324 \pm 367)(\mathrm{p}<0.001$; figure 1 for means).

There were significant correlations between (i) hematoma volume and GCS ( $\mathrm{r}=-0.632 ; \mathrm{p}<0.001)$; (ii) time to admission and GCS ( $r=0.596 ; \mathrm{p}<0.001)$, and (iii) hematoma volume and IVH measured with the Graeb score $(r=0.348 ; p<0.001$; see fig. 2$)$, whereas all other correlations were not significant (data not shown). There were no significant associations between location of ICH and time to admission. Moreover, there was no preferred time of day of admission and no association between time of day of arrival and GCS.

The first multivariate regression model for prediction of time until hospital admission is shown in table $2 \mathrm{a}$ 
Table 1. Patient characteristics and imaging findings of all patients $(\mathrm{n}=157)$

\begin{tabular}{lc}
\hline Patient characteristics & \\
Median age, years & $66(39-93)$ \\
Gender (male/female) & $92 / 65$ \\
Median GCS score & $8(3-15)$ \\
\hline Imaging findings & \\
Volume, cm ${ }^{3}$ & \\
$\quad$ Mean \pm SD & $21.07 \pm 18.24$ \\
Median & $18.4(0.8-166)$ \\
Location & $79[50]$ \\
Deep & $44[28]$ \\
Lobar & $34[22]$ \\
Posterior fossa & $61[39]$ \\
IVH & $4(1-12)$ \\
$\quad$ Graeb score & \\
\hline
\end{tabular}

Figures in parentheses are ranges and values in square brackets percentages.

Table 2. Multivariate logistic regression models (adjusted OR and 95\% CI)

a Parameters predicting time to hospital admission

\begin{tabular}{|c|c|c|c|}
\hline & \multicolumn{2}{|c|}{$\begin{array}{l}\text { Admission } \\
(\geq \text { median } \times \min )\end{array}$} & \multirow[t]{2}{*}{$\mathrm{p}$ value } \\
\hline & OR & $95 \% \mathrm{CI}$ & \\
\hline Hematoma volume, per ml & 0.974 & $0.928-1.023$ & 0.292 \\
\hline Graeb score, per point & 0.542 & $0.359-0.818$ & $<0.004$ \\
\hline GCS, per point & 1.392 & $1.194-1.622$ & $<0.001$ \\
\hline
\end{tabular}

b Parameters predicting favorable clinical presentation

\begin{tabular}{llll}
\hline & \multicolumn{2}{l}{ GCS (9-15) } & \multirow{2}{*}{ p value } \\
\cline { 2 - 3 } & OR & $95 \%$ CI & \\
\hline Hematoma volume, per ml & 0.882 & $0.831-0.935$ & $<0.001$ \\
Graeb score, per point & 0.912 & $0.680-1.225$ & 0.542 \\
Time until admission, per min & 1.007 & $1.002-1.011$ & $<0.004$ \\
\hline
\end{tabular}

Significant parameters are expressed in italics.

(Hosmer-Lemeshow test: 0.871). Significant parameters were (i) presence of IVH (increasing Graeb scores predicted earlier admission), and (ii) GCS, whereas its increase delayed hospital admission (table 2a).

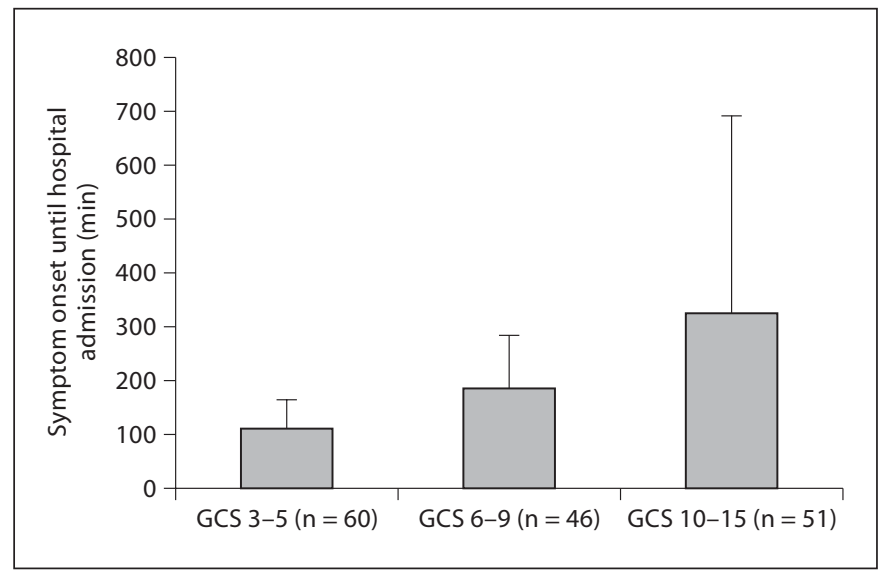

Fig. 1. Time until hospital admission separated with regard to severity of clinical presentation (GCS) of all 157 patients with $\mathrm{ICH}$.

The analysis of predisposing factors for a GCS score of $\geq 9$ on admission also revealed 2 significant parameters (table 2b; Hosmer-Lemeshow test: 0.517). Increasing hematoma volume predicted clinical severity, whereas increasing time to hospital admission predicted a better GCS score.

With regard to all parameters of both models, the exchange of the independent ordinal variable 'Graeb score' with the dichotomized variable 'presence of IVH' neither affected the significance nor resulted in notable alterations of the odds ratios.

\section{Discussion}

In this study we investigated whether specific demographic, clinical and neuroradiological parameters were associated with the time window from symptom onset until hospital admission in patients with spontaneous $\mathrm{ICH}$. As the key finding, throughout data analyses, there were close associations between time to admission and clinical presentation, i.e. the more severely affected a patient was, the earlier hospital admission was observed. Two aspects emerge from the data.

First, as shown for patients with cerebral ischemia, advanced techniques such as expanding the time window for intravenous thrombolysis [22] or other recanalizing procedures [23] are mainly offered in hospitals of maximum medical care and major stroke centers. This raises

Cerebrovasc Dis $2008 ; 25: 533-538$ 
Fig. 2. Correlation between hematoma volume and GCS (a), time to admission and GCS (b), and hematoma volume and Graeb score (c).

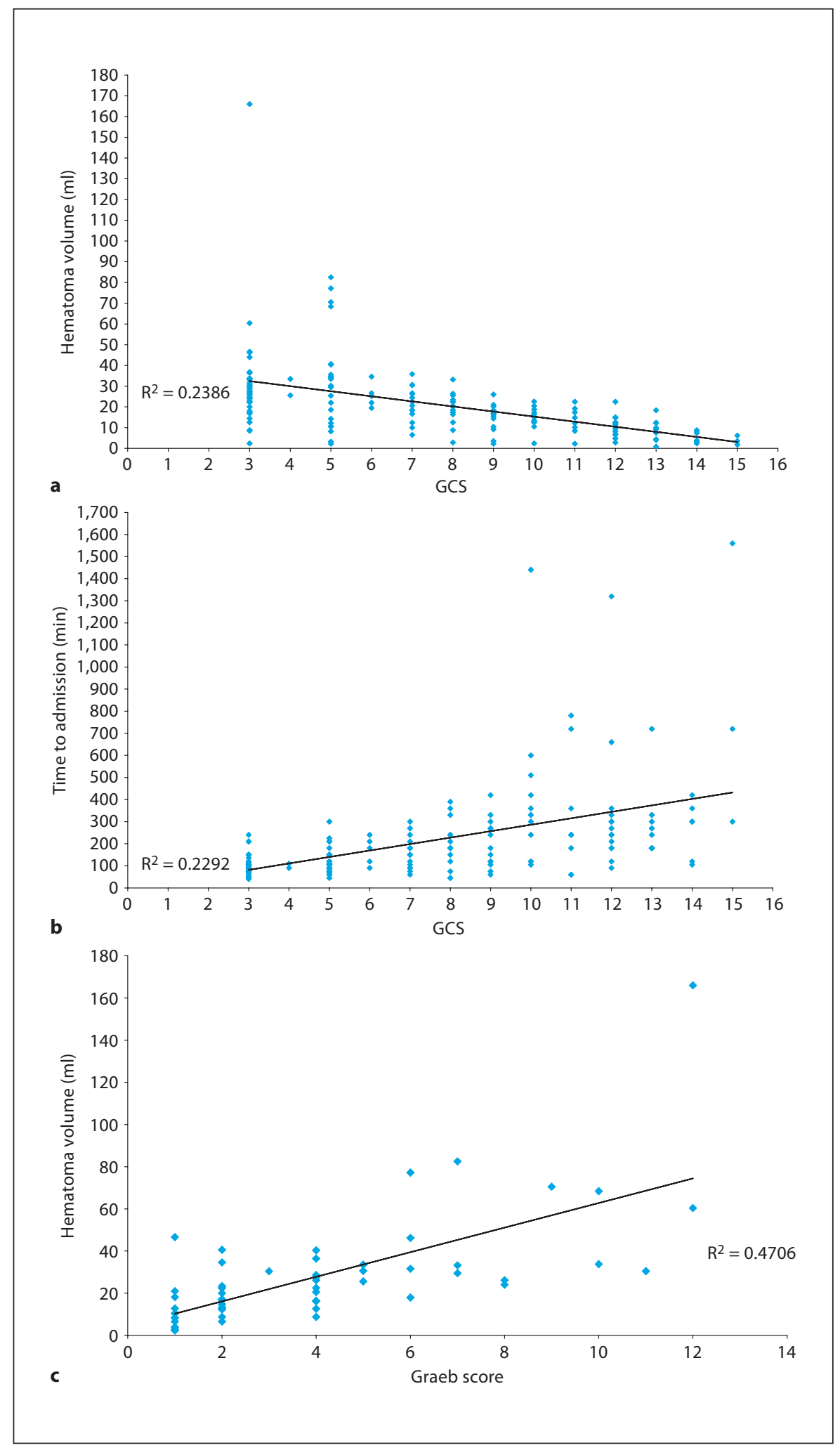


the question whether ICH patients being initially admitted to community hospitals might profit from direct transfer to tertiary hospitals to be immediately subjected to innovative treatments [e.g. hemostatic or neuroprotective drugs [24] as well as specific surgery (e.g. STICH-2; http://www.ncl.ac.uk/stich)] to prevent or minimize hematoma growth. This aspect also holds true for secondary $\mathrm{ICH}$, as the underlying diseases usually require sophisticated support. The earlier admission of patients with accompanying IVH offers a perspective for early intervention with insertion of an intraventricular and lumbar drainage [25], by which moreover fibrinolytic agents may be applied to further improve morbidity [26] (www.clearivh.com). This aspect also supports the idea of rapid transfer of patients with IVH admitted to tertiary hospitals early. Finally, the outcome might further be improved with increasing public awareness of the possible fatality of acute stroke. Patients should immediately seek medical attention and use ambulance transport directly to tertiary hospitals as soon as stroke symptoms occur [27, 28].

Second, with regard to the preliminary data of the Factor VIIa for Acute Hemorrhagic Stroke Treatment (FAST) trial presented recently, the hemostatic therapy using activated recombinant factor VII resulted in a reduction of hematoma growth, however, did not significantly affect the outcome after 3 months [11]. Nevertheless, patients included within $2 \mathrm{~h}$ of symptom onset, and those $<70$ years of age, were characterized by lower Rankin scores at inclusion; their subanalysis revealed benefits for treated patients with regard to both hematoma growth and outcome [11]. This indicates the relevance of immediate treatment in
ICH patients and leads the focus to younger patients with low comorbidity. In addition to these findings, we here show that the clinically worse patients might represent the majority of admitted patients in the hyperacute stages of the disease $[12,13]$. As the initial GCS score is strongly associated with a poor outcome $[1,2]$, patients of the NOVO7 and FAST trials might reflect a collective with a priori assigned favorable prognosis because of their relatively high median GCS score (i.e. 14) [10, 11]. Hence, it remains speculative whether possible outcome differences of the trials escaped significance. Rather, identification of the patients who might profit from early therapy should be promoted [11]. In addition, the expansion of the time window especially with regard to clinically moderately affected individuals may be considered for future hemostatic trials.

A weakness of this study is its nonrandomized and uncontrolled design, which is why patients who were primarily admitted to hospitals of basic medical treatment and subsequently transferred to our universities were not included. Moreover, there was a lack of adequate GCS scoring in the patients whose clinical status was actively worsening and who were not attended by an emergency physician during the transport to hospital.

Taken together, this study discovered that clinically less severely affected patients are admitted to hospital later, although they may reflect an ideal target for therapies such as hemostatic drugs and potential intraventricular fibrinolysis. Thus, regardless of the GCS level, acute stroke patients of all severity degrees should be transferred to tertiary hospitals to be possibly subjected to emerging innovative treatments.

\section{References}

1 Juvela S: Risk factors for impaired outcome after spontaneous intracerebral hemorrhage. Arch Neurol 1995;52:1193-1200.

2 Daverat P, Castel JP, Dartigues JF, Orgogozo JM: Death and functional outcome after spontaneous intracerebral hemorrhage: a prospective study of 166 cases using multivariate analysis. Stroke 1991;22:1-6.

3 McGuire AJ, Raikou M, Whittle I, Christensen MC: Long-term mortality, morbidity and hospital care following intracerebral hemorrhage: an 11-year cohort study. Cerebrovasc Dis 2007;23:221-228.

4 Kazui S, Naritomi H, Yamamoto H, Sawada T, Yamaguchi T: Enlargement of spontaneous intracerebral hemorrhage: incidence and time course. Stroke 1996;27:1783-1787.
5 Brott T, Broderick J, Kothari R, Barsan W, Tomsick T, Sauerbeck L, Spilker J, Duldner J, Khoury J: Early hemorrhage growth in patients with intracerebral hemorrhage. Stroke 1997;28:1-5

6 Jauch EC, Lindsell CJ, Adeoye O, Khoury J, Barsan W, Broderick J, Pancioli A, Brott T: Lack of evidence for an association between hemodynamic variables and hematoma growth in spontaneous intracerebral hemorrhage. Stroke 2006;37:2061-2065.

7 Fujii Y, Tanaka R, Takeuchi S, Koike T, Minakawa T, Sasaki O: Hematoma enlargement in spontaneous intracerebral hemorrhage. J Neurosurg 1994;80:51-57.
8 Qureshi AI, Tuhrim S, Broderick JP, Batjer $\mathrm{HH}$, Hondo H, Hanley DF: Spontaneous intracerebral hemorrhage. N Engl J Med 2001; 344:1450-1460.

9 Mendelow AD, Gregson BA, Fernandes HM, Murray GD, Teasdale GM, Hope DT, Karimi A, Shaw MD, Barer DH: Early surgery versus initial conservative treatment in patients with spontaneous supratentorial intracerebral haematomas in the International Surgical Trial in Intracerebral Haemorrhage (STICH): a randomised trial. Lancet 2005; 365:387-397.

10 Mayer SA, Brun NC, Begtrup K, Broderick J, Davis S, Diringer MN, Skolnick BE, Steiner $\mathrm{T}$ : Recombinant activated factor VII for acute intracerebral hemorrhage. $\mathrm{N}$ Engl J Med 2005;352:777-785. 
11 Mayer SA: Randomized, placebo-controlled, double-blind, multicenter phase III study to assess rFVIIa efficacy in acute intracerebral hemorrhage: the FAST Trial; in American Academy of Neurology, Boston, 2007.

12 Azzimondi G, Bassein L, Fiorani L, Nonino F, Montaguti U, Celin D, Re G, D'Alessandro R: Variables associated with hospital arrival time after stroke: effect of delay on the clinical efficiency of early treatment. Stroke 1997; 28:537-542.

13 Jorgensen HS, Nakayama H, Reith J, Raaschou HO, Olsen TS: Factors delaying hospital admission in acute stroke: the Copenhagen Stroke Study. Neurology 1996;47:383387.

14 Flaherty ML, Woo D, Haverbusch M, Moomaw CJ, Sekar P, Sauerbeck L, Kissela B, Kleindorfer D, Broderick JP: Potential applicability of recombinant factor VIIa for intracerebral hemorrhage. Stroke 2005;36:26602664.

15 Bushnell CD, Phillips-Bute BG, Laskowitz DT, Lynch JR, Chilukuri V, Borel CO: Survival and outcome after endotracheal intubation for acute stroke. Neurology 1999;52: 1374-1381.

16 Schellinger PD, Jansen O, Fiebach JB, Hacke W, Sartor K: A standardized MRI stroke protocol: comparison with CT in hyperacute intracerebral hemorrhage. Stroke 1999;30: 765-768.
17 Pascual AM, López-Mut JV, Benlloch V, Chamarro R, Soler J, Láinez MJ: Perfusionweighted magnetic resonance imaging in acute intracerebral hemorrhage at baseline and during the 1st and 2nd week: a longitudinal study. Cerebrovasc Dis 2007:23:6-13.

18 Kothari RU, Brott T, Broderick JP, Barsan WG, Sauerbeck LR, Zuccarello M, Khoury J: The ABCs of measuring intracerebral hemorrhage volumes. Stroke 1996;27:13041305.

19 Huttner HB, Steiner T, Hartmann M Kohrmann M, Juettler E, Mueller S, Wikner J, Meyding-Lamade U, Schramm P, Schwab $\mathrm{S}$, Schellinger PD: Comparison of $\mathrm{ABC} / 2$ estimation technique to computer-assisted planimetric analysis in warfarin-related intracerebral parenchymalhemorrhage. Stroke 2006;37:404-408.

20 Huttner HB, Schellinger PD, Hartmann M, Kohrmann M, Juettler E, Wikner J, Mueller S, Meyding-Lamade U, Strobl R, Mansmann U, Schwab S, Steiner T: Hematoma growth and outcome in treated neurocritical care patients with intracerebral hemorrhage related to oral anticoagulant therapy: comparison of acute treatment strategies using vitamin K, fresh frozen plasma, and prothrombin complex concentrates. Stroke 2006;37:14651470.

21 Graeb DA, Robertson WD, Lapointe JS, Nugent RA, Harrison PB: Computed tomographic diagnosis of intraventricular hemorrhage: etiology and prognosis. Radiology 1982;143:91-96.
22 Kohrmann M, Juttler E, Fiebach JB, Huttner HB, Siebert S, Schwark C, Ringleb PA, Schellinger PD, Hacke W: MRI versus CTbased thrombolysis treatment within and beyond the $3 \mathrm{~h}$ time window after stroke onset: a cohort study. Lancet Neurol 2006;5: 661-667.

23 Warach S: New imaging strategies for patient selection for thrombolytic and neuroprotective therapies. Neurology 2001;57:S48-S52.

24 Zhao BQ, Tejima E, Lo EH: Neurovascular proteases in brain injury, hemorrhage and remodeling after stroke. Stroke 2007;38:748752.

25 Diringer MN, Edwards DF, Zazulia AR: Hydrocephalus: a previously unrecognized predictor of poor outcome from supratentorial intracerebral hemorrhage. Stroke 1998;29: 1352-1357.

26 Huttner HB, Schwab S, Bardutzky J: Lumbar drainage for communicating hydrocephalus after ICH with ventricular hemorrhage. Neurocrit Care 2006;5:193-196.

27 Wester P, Radberg J, Lundgren B, Peltonen M, Seek Medical Attention in Time Study Group: Factors associated with delayed admission to hospital and in-hospital delays in acute stroke and TIA: a prospective, multicenter study. Stroke 1999;30:40-48.

28 Williams LS, Bruno A, Rouch D, Marriott DJ: Stroke patients' knowledge of stroke: influence on time to presentation. Stroke 1997; 28:912-915. 